\title{
DAMPAK PENGGUNAAN GADGET BAGI PERKEMBANGAN SOSIAL ANAK SEKOLAH DASAR
}

\author{
Yummi Ariston ${ }^{1}$ Frahasini $^{2}$ \\ Keywords : \\ Dampak Gadget; \\ Perkembangan Sosial Anak \\ Sekolah Dasar.
}

Pendidikan Guru Sekolah Dasar, STKIP Singkawang, Singkawang, Indonesia aristonyummi@gmail.com ${ }^{1}$, frahasini_isin@yahoo.co.id ${ }^{2}$

\begin{abstract}
Penggunaan gadget dapat berdampak bagi perkembangan sosial anak. Penulisan artikel ini bertujuan untuk mengkaji dan menganalisis dampak dari penggunaan gadget bagi perkembangan sosial anak sekolah dasar. Artikel ini merupakan hasil analisis dengan mengkaji literatur yang memiliki keterkaitan dengan topik pembahasan. Model yang digunakan adalah studi literatur atau lirature riview. Dari hasil penelaahan, menunjukan bahwa sebagian besar anak menggunakan gadget hanya untuk bermain game dan menonton film animasi yang seharusnya gadget dapat dipergunakan untuk media pembelajaran bagi anak. Dalam hal ini sangat diperlukan pengawasan oleh orang tua untuk memonitoring kegiatan anak dalam menggunakan gadget sehari-hari untuk meminimalisir sisi negatif dari dampak penggunaan gadget pada anak serta guru sebagai dan sudah seharusnya anak lebih baik diarahkan kedalam kegiatan yang memiliki aktivitas dilingkungan agar mudah untuk bersosialisasi.
\end{abstract}

\section{INTRODUCTION}

Penggunaan gadget tidak hanya di kalangan orang dewasa saja, melainkan pada para remaja hingga anak-anak. Tentu saja hal ini bukan hanya terjadi tanpa alasan karena daya dan sifat yang konsumtif dan kebutuhan masyarakat saat ini sudah jauh berbeda dibandingkan beberapa dekade ke belakang. Dewasa ini, anak-anak sudah akrab dengan gadget. Tidak terkecuali pada anak sekolah dasar. Menurut Rosalina (dalam Admin Ridwan 2017:2) "Peserta didik Sd adalah mereka yang berusia sekitar 6 s/d 12 tahun yang sedang menjalani tahap perkembangan masa anak-anak dan akan memasuki masa remaja awal". Pada masa ini sudah seharusnya anak sekolah dasar mengisi waktunya dengan hal-hal yang dapat membantu mendorong perkembangan otak dan sosial anak seperti bermain dan belajar. Dalam bermain dan belajar harus terdapat keselarasan, artinya tidak ada sifat monoton pada keduanya. Anak dapat bermain sambil belajar maupun belajar melalui permainan. Permainan elektronik di komputer video game mampu menarik dan menghipnotis hati anak, seperti playstation, game online, dan gamegame dari gadget terbuka. Bahkan kadang anak tidak memperdulikan lingkungan sekitarnya karena terlalu asik dengan game yang dimainkannya. Pentingnya pengawasan dan kontrol pada anak dalam penggunaan gadget, khususnya dilingkungan keluarga yaitu orang tua yang mempunyai peran pertama dalam pembentukan karakter dan tumbuh kembang anak, dimana pemberian dan penggunaan gadget pada anak seharusnya memiliki batasan dan aturan yang jelas. Pada lingkungan sekolah dasar, guru 
sebagai orang tua disekolah harus dapat melayani dan membimbing peserta didik. Tanpa memandang latar belakang siswa baik suku, rasa, agama, status sosial dan sebagainya.

Pada dasarnya, gadget belum waktunya untuk diberikan pada anak-anak seperti telepon seluler pribadi, hal ini dikarenakan dapat memicu perilaku konsumtif yang berlebih pada anak. Memang anak-anak sekolah dasar masih sangat dilarang atau memerlukan pengawasan yang ketat dalam menggunakan gadget dalam aktivitas sehari-hari mereka. Oleh karena itu orang tua harus lebih bijak dalam memberikan alat penunjang untuk kebutuhan anaknya serta selalu mengontrol setiap konten yang ada di gagdet anak-anaknya. Sering kali orang tua menjadikan gadget sebagai salah satu jalan pintas orang tua dalam pendamping anaknya. Dengan berbagai fitur dan aplikasi yang menarik orang tua memanfaatkannya untuk menemani anak agar orang tua dapat menjalankan aktivitas dengan tenang, tanpa khawatir anaknya bermain kotor, memberantakan rumah sehingga mengganggu aktivitas orang tua. Hal ini adalah keliru, karena dapat berdampak buruk bagi perkembangan anak. Jangan sampai orang tua bersikap tidak peduli dan mengandalkan gadget sebagai alat untuk menemani anak. Orang tua harus bisa mengkomunikasikan dan berdiskusi kepada anak-anaknya mengenai isi atau konten yang terdapat di gadget anak-anaknya.

Kemudahan untuk mengakses informasi seperti pada smartphone, membuat anak-anak cenderung kesulitan memilih hal yang memang disajikan untuk anak-anak atau orang dewasa. Dari kemudahan tersebut, menimbulkan rasa ingin tahu anak mengenai konten-konten dewasa yang mengarah pada tindakan kriminal atau asusila, sehingga membuat mereka ingin melakukannya.

\section{METHOD}

Artikel ini menggunakan studi literatur atau literature riview dengan menganalisis beberapa kajian yang berkaitan dengan topik pembahasan yaitu dampak penggunaan gadget dan perkembangan sosial anak. Sumber-sumber rujukan yang menjadi pokok bahasan bersumber dari buku, jurnal artikel, prosiding dan yang lainnya. Hal tersebut dimaksudkan untuk meninjau dampak penggunaan gadget bagi perkembangan sosial anak.

\section{RESULTS AND DISCUSSIONS}

\section{Gadget}

Gadget adalah sebuah istilah bahasa inggris yang mengartikan sebuah perangkat atau instrumen elektronik yang memiliki tujuan dan fungsi khusus terutama untuk membantu manusia dalam menjalankan aktivitasnya. Menurut Hana Pebriana (2017:3) menyatakan "Gadget adalah perangkat elektronik kecil yang memiliki fungsi khusus. Diantaranya smartphone seperti iphone dan blackberry, serta netbook (perpaduan antara komputer portabel seperti notebook dan internet". Gadget mempunyai fungsi dan manfaat yang relatif sesuai dengan penggunaanya seperti menurut Puji Asmaul Chusna (2017:318-319) Fungsi dan manfaat gadget secara umum diantaranya:

1. Komunikasi

Pengetahauan manusia semakin luas dan maju. Jika zaman dahulu manusia berkomunikasi melalui batin, kemudian berkembang melalui tulisan yang dikirimkan melalui pos. Sekarang zaman era globalisasi manusia dapat berkomunikasi dengan mudah, cepat, praktis dan lebih efisien dengan menggunakan handphone.

2. Sosial

Gadget memiliki banyak fitur dan aplikasi yang tepat untuk kita dapat berbagi berita, kabar, dan cerita. Sehingga dengan pemanfaatan tersebut dapat menambah teman dan menjalin hubungan kerabat yang jauh tanpa harus menggunakan waktu yang relatif lama untuk berbagi.

3. Pendidikan 
Seiring berkembangnya zaman, sekarang belajar tidak hanya terfokus dengan buku. Namun melalui gadget kita dapat mengakses berbagai ilmu pengetahuan yang kita perlukan. Tentang pendidikan, politik, ilmu pengetahuan umum, agama, tanpa harus repot pergi ke perpustakaan yang mungkin jauh untuk dijangkau.

\section{Perkembangan Sosial Anak Sekolah Dasar}

Menurut Farida Mayar (2013:460) mengatakan "Perkembangan sosial merupakan pencapaian kematangan dalam hubungan sosial". Ia mengartikan bahwa perkembangan sosial sebagai proses belajar untuk menyesuaikan diri terhadap norma, moral dan tradisi: Meleburkan diri menjadi suatu kesatuan yang saling berkomunikasi dan bekerjasama. Umi Latifa (2017:194), mengatakan bahwa "Karakteristik perkembangan seseorang berbeda-beda, tergantung faktor yang memengaruhi perkembangan seseorang".

Pada awalnya, tingkah laku sosial anak dipengaruhi dari lingkungan keluarganya. Kemudian perkembangannya dipengaruhi dari lingkungan sekolah dan masyarakat. Perlakuan dan bimbingan orang tua pada anak sangat berpengaruh pada perkembangan sosialnya diberbagai aspek kehidupan sosial atau norma-norma kehidupan bermasyarakat serta dapat mendorong dan memberikan contoh kepada anaknya bagaimana hidup sebagai makhluk sosial dan menerapkan norma-norma dalam kehidupan sehari-hari. Yusmi Warisyah (2018:131) mengatakan bahwa "Penggunaan Internet dikalangan anak-anak semakin memprihatinkan dan tentu memiliki dampak negatif terhadap tumbuh kembang". Menurutnya anak-anak lebih cepat beradaptasi dengan teknologi yang ada dan sering terlena dengan kecanggihan gadget yang tersedia fitur-fitur didalamnya.

Penggunaan gadget yang berlebihan akan berdampak buruk bagi anak. Anak yang menghabiskan waktunya dengan gadget akan lebih emosional, bahkan dapat membentuk sikap pemberontak pada anak karena merasa diganggu saat orang lain maupun orang tuanya yang berbicara maupun bermaksud berinteraksi secara fisik pada anak saat anak sedang asyik bermain gadget seperti game. Malas mengerjakan rutinitas sehari-hari seperti belajar. Bahkan untuk makanpun harus disuap.

Perkembangan usia anak sekolah dasar merupakan tahap perkembangan dimana pada masa ini anak-anak tengah mempersiapkan dirinya demi kelangsungan hidup mereka yang akan mendatang. "Anak atau peserta didik adalah pribadi yang tumbuh dan berkembang menuju kedewasaannya" (Amin Ridwan 2017:2). Menurutnya, seiring bertambahnya usia, peserta didik akan mengalami proses belajar dari yang sebelumnya tidak tahu menjadi tahu.

\section{Penggunaan Gadget Bagi Perkembangan Sosial Anak Sekolah Dasar}

Pengaruh penggunaan gadget terhadap perkembangan anak memiliki dampak positif dan dampak negatif. Adapun dampak positifnya antara lain menambah pengetahuan anak, membangun dan melatih kreativitas anak, mempermudah berkomunikasi, maupun memperluas jaringan persahabatan. Penggunaan gadget sewajarnya telah membantu anakanak dalam kesehariannya terutama dalam mencari data maupun informasi untuk mengerjakan tugas sekolah maupun sebagai sarana hiburan dari fitur-fitur yang disediakan dalam gadget. Sedangkan dampak negatifnya antara lain, anak menjadi ketergantungan terhadap gadget, sehingga dalam menjalankan segala aktivitas hidupnya anak menjadi sulit berinteraksi dengan lingkungan sekitarnya. Penggunaan gadget secara berlebihan dapat 
mengganggu kesehatan mata, anak menjadi malas bergerak dan beraktivitas serta lebih suka bermain dengan gadgetnya daripada bermain dengan temannya.

Iswanto dan Onibala (dalam Yusmi Warisyah 2015:131) mendefenisikan, "Anak-anak yang sering menggunakan gadget, sering kali lupa dengan lingkungan sekitarnya, mereka lebih memilih bermain menggunakan gadget dari pada bermain bersama teman-teman dilingkungan sekitar tempat tinggal". Dampak lainnya adalah semakin meluas dan terbukanya akses internet dalam gadget yang menampilkan segala hal beberapa diantaranya merupakan suatu hal yang semestinya belum waktunya dilihat oleh anak-anak. Pada usia anak sekolah dasar tentu akan menganggu proses kegiatan belajar mereka di sekolah, dimana anak membutuhkan hubungan sosial yang baik seperti interaksi pada teman dan gurunya. Penggunaan gadget yang berlebihan pada anak akan menimbulkan sifat egois dan indivudualisme. Menurut Adek Diah Saputri (2018:277) mengatakan bahwa "Dampak negatif dari penggunaan gadget adalah anak cenderung untuk individualis, susah bergaul dan apabila sudah kecanduan akan sangat sulit untuk dikontrol dari pemakaian gadget yang pada akhirnya otak anak-anak sulit berkembang karena terlalu sering bermain game".

Penggunaan gadget secara terus-menerus akan menimbulkan kecanduan pada penggunanya. Hal ini tentu perlu menjadi perhatian karena dampak negatif yang begitu mengkhawatirkan terlebih bagi anak-anak yang menggunakan gadget. Maka dari itu peran orang tua sangat penting dalam memberikan dan melakukan pengawasan dan pengontrolan penggunaan gadget pada anak. "Keluarga disarankan untuk lebih memperhatikan penggunaan gadget pada anak saat dirumah dengan cara memberikan batasan waktu untuk bermain gadget pada anak saat dirumah dengan melakukan hal yang menarik seperti mengajak bermain diluar rumah, ajak anak untuk lebih banyak beraktivitas (olahraga, bermain musik, dll), dan bersosialisasi dengan teman sebayanya" (Setianingsih, dkk 2018:201).

Menurut Fadilah (dalam Yusmi Warisyah 2015:137) "Hal-hal yang dilakukan orang tua untuk meminimalisir anak dari pengaruh negatif penggunaan gadget (1) Mendampingi anak (2) Membuat kesepakatan waktu dalam penggunaan gadget (3) Membuat kesepkatan dalam membuka fitur-fitur yang akan dibuka (4) Modelling yang baik dari orang tua (5) Orang tua dapat menaruh gadget dengan baik (7) Mengajak anak untuk belajar bersama”. Orang tua harus dapat mendidik dan mengarahkan anaknya sejak dini melalui sikap dan perbuatan yang sepatutnya dicontoh oleh anak-anaknya. "Peran orang tua dalam mengawasi penggunaan gadget untuk anak-anak SD/ sederajat adalah dilakukan melalui pengawasan waktu dan pengawasan akses yang digunakan oleh anak-anak melalui gadget, tingkat SMP/sederajat adalah masih dikontrol hanya tidak seperti anak sekolah dasar, saat di sekolah menengah/pendidikan yang setara dengan mengawasi kegiatan anak-anak dalam menggunakan gadget yang tidak menahan" (Frahasini dkk 2018:167).

Selain orang tua, di sekolah diperlukan peran guru sebagai pendidik yang dapat memberikan arahan dan bimbingan pada anak berupa ilmu maupun motivasi. Menurut Rukaiah Proklamasi Hasibuan (2017:401) mengatakan "Guru sejatinya seorang pribadi yang harus serba bisa dan serba tahu, serta mampu mentransferkan kebiasaan pengetahuan pada muridnya dengan cara yang sesuai dengan perkembangan dan potensi anak didik". Pada dasarnya guru memang mengemban peran yang banyak bagi peserta didiknya, guru harus dapat memahami karakteristik pada peserta didiknya. 
Berdasarkan beberapa pendapat diatas dapat ditarik kesimpulan bahwa penggunaan gadget khususnya pada anak sekolah dasar dapat berdampak bagi perkembangan sosial mereka. Dalam hal ini, orang tua dan guru sangatlah berperan penting dalam mengontrol dan mengawasi maupun memberikan bimbingan pada anak terkait penggunaan gadget.

\section{CONCLUSION AND SUGGESTION}

Perkembangan teknologi semakin pesat, salah satu diantaranya adalah dengan adanya gadget yang semakin canggih. Beberapa contoh gadget diantaranya Laptop, Netbook, Smartphone, Tablet, dan masih banyak lagi. Dengan gadget sangat membantu manusia dalam menjalankan kehidupan sehari-harinya seperti bekerja dan sekolah. Akan tetapi gadget juga mempunyai dampak negatif dan buruk. Penggunaan gadget pada anak sekolah dasar dapat berdampak bagi perkembangan sosialnya, seperti lupa dengan lingkungan sekitarnya dan kurangnya waktu bermain bersama teman-temannya. Maka dari itu orang tua sangatlah berperan penting dalam hal ini karena sudah sepatutnya orang tua mengajarkan dan mengarahkan anak-anaknya pada hal-hal yang dapat membangun dan mengembangkan pengetahuan dan karakter anak dengan memperhatikan faktor-faktor yang dapat berdampak buruk bagi perkembangan sosial anak. Guru disekolah dasar dapat membimbing dan menuntun serta mengarahkan pada suatu pemahaman konsep bagi anak sekolah dasar.

\section{REFERENCES}

Asmaul Chusna, Puji. (2017). PENGARUH MEDIA GADGET PADA PERKEMBANGAN KARAKTER ANAK. Jurnal Dinamika Penelitian: Media Komunikasi Penelitian Sosial Keagamaan 17(2), 315-330.

Diah Saputri, Adek dkk. (2018). Dampak Penggunaan Gadget Terhadap Kemampuan Intraksi Sosial Anak Usia Dini. Online ISSN (e-ISSN): 2548-4516 Volume 3.

Frahasini dkk. (2018). The Impact of The use of Gadgets in School of School Age Towards Children's Social Behavior in Semata Village. Journal of Educational Social Studies 7 (2), 161-168.

Hana Pebriana, Putri. (2017). Analisis Penggunaan Gadget Terhadap Kemampuan Interkasi Soaial Pada Anak Usia Dini. Jurnal Obsesi: Jurnal Pendidikan Anak Usia Dini 1 (1), 111.

Latifa, Umi. (2017). Aspek Perkembangan pada Anak Sekolah Dasar:Masalah dan Perkembangannya. Academica: Journal of Multidisciplinary Studies 1 (2), 185-196.

Mayar, Farida. (2013). PERKEMBANGAN SOSIAL ANAK USIA DINI SEBAGAI BIBIT UNTUK MASA DEPAN BANGSA. Al-Ta'lim Journal 20 (3), 459-464.

Proklamasi Hasibuan, Rukiah. (2017). PERAN GURU DALAM PENDIDIKAN. Prosiding Seminar Nasional Tahunan Fakultas Ilmu Sosial Universitas Negeri Medan 1.

Ridwan, Admin. (2017). PERAN GURU AGAMA DALAM BIMBINGAN KONSELING SISWA SEKOLAH DASAR. Risâlah, Jurnal Pendidikan dan Studi Islam 4 (1), 1-13.

Setianingsih, dkk. (2018). DAMPAK PENGGUNAAN GADGET PADA ANAK USIA PRASEKOLAH DAPAT MENINGKATKAN RESIKO GANGGUAN PEMUSATAN PERHATIAN DAN HIPERAKTIVITAS. Gaster: Jurnal Kesehatan 16 (2), 191-205.

Warisyah, Yusmi. (2015). PENTINGNYA "PENDAMPINGAN DIALOGIS" ORANG TUA DALAM PENGGUNAAN GADGET PADA ANAK USIA DINI. Seminar Nasional Pendidikan, 130-138. 
Prihatiningtyas, Nindy C. \& Nurhayati. (2017). Penerapan Model Pembelajaran Means-Ends Analysis Untuk Meningkatkan Kemampuan Pemecahan Masalah Matematis Siswa. JPMI (Jurnal Pendidikan Matematika Indonesia), 2(1), 13-18.

Romli, Muhammad. (2016). Profil kemampuan koneksi matematis siswa perempuan SMA dengan kemampuan tinggi dalam menyelesaikan masalah matematika. Journal of mathematics education, science \& tehnology. 1(2), 145-157.

Sugiman. (2008). Koneksi Matematik dalam Pembelajaran Matematika di Sekolah Menengah Pertama. Jurnal Pendidikan Matematika. 4(1), 56-66.

Sundayana. (2014). Statistika Penelitian Pendidikan. Bandung: Penerbit Alfabeta

Warih, dkk. (2016). Analisis Kemampuan Koneksi Matematis Siswa Kelas VIII Pada Materi Teorema Phytagoras. In Prosiding Konferensi Nasioanal Penelitian Matematika dan Pembelajarannya (KNPMP 1). Diselenggarakan oleh Program Studi Pendidikan Matematika, UMS, 12 Maret 2016, (hal. 377-384). Muhammadiyah University Press. Diakses dari https://publikasiilmiah.ums.ac.id/hadle/2502/6526

Widarti (2013). Kemampuan Koneksi Matematis dalam Menyelesaikan Masalah Kontekstual Ditinjau dari Kemampuan Matematis siswa. Skripsi. Pendidikan Matematika STKIP PGRI Jombang.

Yuniawati. (2011). Penerapan Pembelajaran Matematika dengan Strategi React untuk meningkatkan kemampuan koneksi dan Representasi Matematis Siswa Sekolah Dasar. Jurnal Edisin Khusus No 2 